\title{
The bcet gene of Bacillus cereus encodes an enterotoxic protein
}

\author{
Norio Agata, ${ }^{1}$ Michio Ohta, ${ }^{2}$ Yoshichika Arakawa ${ }^{2}$ and Masashi Mori ${ }^{1}$
}

Author for correspondence: Norio Agata. Tel: +8152841 1511, ext. 51. Fax: +81528411514.

\footnotetext{
1 Nagoya City Public Health Research Institute, 1-11 Hagiyamacho, Mizuhoku, Nagoya 467, Japan

2 Department of Bacteriology, Nagoya University School of Medicine, 65 Tsurumaicho, Showaku, Nagoya 466, Japan
}

\begin{abstract}
A toxin gene (bcen) on a 2.9 kb DNA fragment of Bacillus cereus B-4ac was cloned and expressed in Escherichia coli, and its nucleotide sequence determined. The DNA fragment contained an open reading frame capable of encoding a polypeptide of 336 amino acids with a molecular mass of $41039 \mathrm{Da}$. The translated product in E. coli exhibited Vero cell cytotoxicity, and was positive in a vascular permeability assay. It also caused fluid accumulation in a ligated mouse ileal loop and was lethal to mice upon injection. These biological activities are considered characteristic of diarrhoeal enterotoxins. We therefore conclude that this gene, designated bceT, encodes one of the enterotoxic proteins of $B$. cereus which cause food-borne diarrhoea.
\end{abstract}

Keywords: Bacillus cereus, food poisoning, enterotoxic protein, bceT gene

\section{INTRODUCTION}

The association of Bacillus cereus with food-borne illness has been comprehensively reported (Kramer \& Gilbert, 1988; Turnbull et al., 1979a). This organism causes two different types of human gastroenteritis (Turnbull, 1976; Turnbull et al., 1979b). The ability of B. cereus to cause diarrhoea is attributed to the production of an enterotoxin (B. cereus diarrhoeal enterotoxin, designated bc-D-ENT in this study) (Gilbert \& Kramer, 1984; Turnbull, 1981). bcD-ENT is capable of causing fluid accumulation in ligated rabbit ileal loops (Punyashthiti \& Finkelstein, 1971), altering the vascular permeability of guinea-pig skin (Glatz \& Goefert, 1973), and showing cytotoxicity towards Vero cells (African Green monkey kidney cells) (Konowalchuk et al., 1977). Purification of the fractions relevant to these biological properties has been attempted, and some components have been partially characterized (Bonventre, 1965; Shinagawa et al., 1991; Spira \& Goefert, 1975; Thompson et al., 1984). These studies suggest that all these biological activities are due to a single entity. Thompson et al. (1984) suggested that the enterotoxic activity probably comprised more than one component, and Beecher \& Macmillan (1991) reported that three components of haemolysin BL also composed the diarrhoeal enterotoxin. However, other studies, such as those of Turnbull et al. (1979b) and Shinagawa et al.

\footnotetext{
Abbreviation: bc-D-ENT, Bacillus cereus diarrhoeal enterotoxin.
}

The GenBank accession number for the nucleotide sequence reported in this paper is D17312.
(1991), identified a single relatively unstable protein of 43-50 $\mathrm{kDa}$ which was responsible for the diarrhoeal-type $B$. cereus food poisoning. To resolve the contradiction among these results, we have cloned and sequenced the structural gene encoding a protein which has the biological activities of bc-D-ENT.

\section{METHODS}

Bacterial strains, antiserum, plasmids, and growth conditions. Escherichia coli strains for DNA manipulation were routinely cultured in LB medium (Miller, 1992) with aeration. $B$. cereus strains listed in Table 1 were grown in BHI broth (Difco). Antiserum against a crude preparation of $B$. cereus enterotoxin was prepared according to Spira \& Goefert (1975). Plasmid pHSG299 was used for cloning, and bacteriophages M13 mp18 and mp19 for sequencing. pHSG299 is a kanamycin-resistant derivative of $\mathrm{pUC} 19$ and therefore carries the lac promoter-lac $Z$ of pUC19 (Takeshita et al., 1987). Expression of a DNA insert at the polycloning site should be under the control of the lac $Z$ promoter. Kanamycin (Sigma) was added to liquid and solid media at $50 \mu \mathrm{g} \mathrm{ml}^{-1}$ for selection of recombinant clones. In addition, to screen for the insertional inactivation of the LacZ peptide encoded by the vectors, $50 \mu \mathrm{M}$ isopropyl $\beta$-Dthiogalactoside (IPTG; Sigma) and 0.01\% 5-bromo-4-chloro-3indolyl $\beta$-galactoside (X-Gal; Sigma) were added to the media. DNA manipulation. Extraction and purification of plasmid DNA and double-stranded phage DNA, and purification of single-strand phage DNA for sequencing were performed by published methods (Gilmore et al., 1985; Maniatis et al., 1982). Chromosomal DNA from B. cereus B-4ac was prepared by the method of Dubnau \& Davidoff-Abelsen (1971). All other manipulations with DNA, such as enzyme digestion, ligation, and transformation of bacteria, were performed as described by Maniatis et al. (1982). 
Western blot analysis. The lysate of E. coli cells was analysed by SDS-PAGE according to the method of Laemmli (1970). To prepare the lysate, $E$. coli cells were cultured for $15 \mathrm{~h}$ with constant shaking in $100 \mathrm{ml} \mathrm{LB}$ medium containing $0.01 \%$ IPTG and $50 \mu \mathrm{g}$ kanamycin $\mathrm{ml}^{-1}$, then harvested by centrifugation. The cell pellet was suspended in $5 \mathrm{ml} 30 \mathrm{mM}$ Tris buffer $\mathrm{pH} 8.0 / 50 \mathrm{mM} \mathrm{NaCl}$ containing $50 \mathrm{mg}$ lysozyme (Sigma). After incubation at $37^{\circ} \mathrm{C}$ for $1 \mathrm{~h}$, the suspension was centrifuged for $15 \mathrm{~min}$ at $8000 \mathrm{~g}$ and the supernatant was used as the crude preparation. The proteins separated by $0.1 \%$ SDS $/ 10 \%(\mathrm{w} / \mathrm{v})$ polyacrylamide gel electrophoresis were transferred electrophoretically to nitrocellulose paper (Bio$\mathrm{Rad})$. The blots were probed with rabbit antiserum against diarrhoeal enterotoxin. The antiserum was pretreated with a lysate of E. coli JM109 to remove non-specific staining. Binding of the primary antibody was detected by using goat anti-rabbit immunoglobulin $G$ conjugated to horseradish peroxidase (Cappel).

Sequencing. DNA fragments were subcloned into M13 mp18 or mp19 and used as templates for nucleotide sequencing by the dideoxynucleotide fluorescence labelling method (Applied Biosystems DNA Sequencer model 370A) using Taq DNA polymerase.

Assay for biological activities of the cell lysate. An IPTGinduced cell lysate of E. coli JM109 carrying a recombinant clone was used as a crude preparation of the gene product.

Mouse ileal loop (MIL) assay. The MIL technique was performed as described by Punyashthiti \& Finkelstein, 1971). Although not ideal, the MIL model offers some advantages over the rabbit ileal loop test and is becoming more widely used (Shinagawa $e t$ al., 1991). Briefly, ICR mice weighing 17-22 g were anaesthetized lightly with ether. The abdomen was opened and, from a point approximately $8 \mathrm{~cm}$ distal to the stomach, two $6 \mathrm{~cm}$ loops, separated from each other by an interloop of $1 \mathrm{~cm}$, were isolated by silk ligatures, taking care to avoid blood vessels. Intraluminal injection of $0.2 \mathrm{ml}$ of a sample was made into one test loop; the other loop was injected with a suitable control. The ileum was then replaced into the abdominal cavity, and the incision was sutured. After $6 \mathrm{~h}$, the mice were killed, the abdominal cavities were opened immediately and the length of the excised loops and the fluid volume accumulated in the ligated ileal loops were measured. The results were judged positive when the ratio of fluid to length was $50 \mathrm{mg} / \mathrm{cm}$ or more.

Vascular permeability (VP) assay. VP activity was determined by the method of Glatz \& Goefert (1973). Each sample $(0.1 \mathrm{ml})$ was dialysed against phosphate buffer $(0.02 \mathrm{M}, \mathrm{pH} 7 \cdot 0)$, adjusted to $0.2 \mathrm{ml}$ volume, and injected $(0.05 \mathrm{ml})$ in duplicate into at least two female New Zealand White rabbits. After $3 \mathrm{~h}$, each animal was injected intravenously with $2 \mathrm{ml}$ of a $10 \%$ (w/v) solution of Evans blue prepared in $0.9 \% \mathrm{NaCl}$; reactions were read after an additional $1 \mathrm{~h}$.

Mouse lethal (ML) activity. In the assay for ML activity (Glatz \& Goefert, 1973), two mice were tested per sample. Death of mice within 30 min after injection of $0.5 \mathrm{ml}$ of the test sample into the caudal vein was considered a positive reaction.

Cytotoxicity (CT) activity. C'T assay to Vero cells was performed by the method of Konowalchuk et al. (1977) with several modifications. Cells were maintained in Dulbecco modified Eagle medium (Gibco Laboratories) supplemented with $3.5 \mathrm{mg}$ glucose $\mathrm{ml}^{-1}$ and $10 \%(\mathrm{v} / \mathrm{v})$ foetal calf serum. Cells were split 1:6 into 24 -well plates $3 \mathrm{~d}$ before test. Cell density for the test was $10^{5}$ cells $\mathrm{cm}^{-2}$. Test samples $(0.5 \mathrm{ml})$ were dialysed against phosphate buffer $(0.02 \mathrm{M}, \mathrm{pH} 7.0)$, adjusted to $1 \mathrm{ml}$ volume, and passed through a $0 \cdot 22 \mu \mathrm{m}$ Millex (Nihon Millipore Kogyo K.K., Yonezawa, Japan); $100 \mu \mathrm{l}$ was then added to each well. Cells were incubated in $5 \%(\mathrm{v} / \mathrm{v}) \mathrm{CO}_{2}$ at $36{ }^{\circ} \mathrm{C}$. After $12 \mathrm{~h}$, observations were made for the disruption of the cell monolayer.

Assay units. Activities in the MIL and VP assays were expressed as diarrhoeagenic units (DU) and VP factor units (PFU), respectively, and were calculated on the basis of the standard curves (Glatz et al., 1974). ML dose (MLD) and CT dose were expressed as the reciprocal of the highest dilutions of the lysate to give positive reactions in these assays.

Polymerase chain reaction (PCR). The oligonucleotide primers were synthesized on a commercial DNA synthesizer (391 DNA Synthesizer; ABI). The DNA sequences for the PCR primers used were as follows: a forward primer which corresponds to nucleotide positions 1354-1374 (5'-TTACATTACCAGGACGTGCTT-3'), and a reverse primer corresponding to the complement of positions 1761-1781 (5'-TGTTTGTGATTGTAAT'TCAGG-3'). Amplification was carried out in a DNA thermal cycler (Perkin-Elmer Cetus) for 25 reaction cycles of $1 \mathrm{~min}$ at $94^{\circ} \mathrm{C}$ (denaturation), $2 \mathrm{~min}$ at $55^{\circ} \mathrm{C}$ (annealing), and $2 \mathrm{~min}$ at $72{ }^{\circ} \mathrm{C}$ (extension-polymerization).

\section{RESULTS}

\section{Cloning of an enterotoxin gene}

B. cereus B-4ac is an isolate from a food poisoning outbreak. To identify the genes involved in biosynthesis of $B$. cereus diarrhoeal enterotoxins, a gene library of B-4ac was constructed. Chromosomal DNA from B-4ac was extracted, partially digested with EcoRI and PstI, and ligated to the EcoRI-PstI site of the plasmid vector pHSG299. From about 2000 transformants of E. coli JM109 screened by immunoblot analysis with antidiarrhoeal enterotoxin rabbit antiserum, two antigenically positive clones were identified. By the preliminary assays for the biological activities of the diarrhoeal enterotoxin, only one clone, designated pAGA118, was found to be positive.

\section{Nucleotide sequence determination}

The size of the insert in the EcoRI-PstI site of pAGA118 was $2.9 \mathrm{~kb}$. The physical map of the insert is shown in Fig. 1. DNA fragments resulting from digestion with appropriate restriction enzymes were subcloned into the same sites of M13 vectors mp18 and mp19. These subclones were sequenced by the dideoxynucleotide chaintermination method. For the portions where no suitable

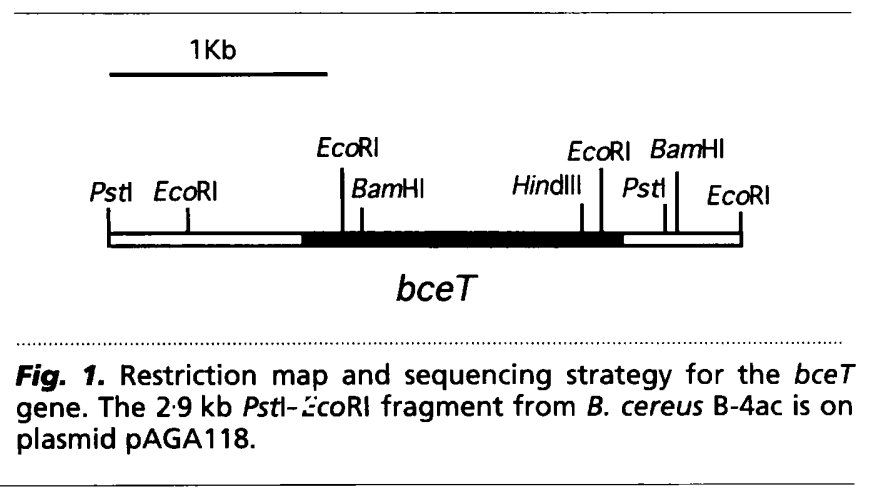


restriction sites were available, synthetic oligonucleotide primers were synthesized. The complete nucleotide sequence was thus determined on both strands with full overlap (Fig. 2). As shown in Fig. 2, a search for open reading frames (ORFs) by computer analysis revealed an ORF coding for 336 amino acid residues (molecular mass $41039 \mathrm{Da})$. Tn 5 insertions in the ORF using the $\operatorname{Tn} 5$ plasmid pCHR81 (Ohta et al., 1991), although the precise positions of the insertion sites were not determined, abolished the enterotoxigenic activities (data not shown). This ORF was therefore designated bce T. Immediately upstream of the translation initiation codon, there is a putative ribosome-binding site CAGAA with weak homology to the $16 \mathrm{~S}$ rRNA-binding site (Fig. 2). Immediately upstream of the putative translation initiation codon, there are three directly repeated sequences, each of which includes a stem-loop structure, a potential transcription terminator. A search of the GenBank and EMBL databases revealed no other genes with homologous nucleotide sequences. Homology searches for amino acid sequences in the NBRF database identified no proteins with significant homology either.

\section{Detection of the bceT gene product by Western blot analysis}

A cell lysate of E. coli JM109(pAGA118) was analysed by SDS-PAGE. A $41 \mathrm{kDa}$ protein was detected on SDSPAGE after IPTG induction (Fig. 3a, lane 2). This induced protein was also detected in Western blot analysis using antiserum against a crude enterotoxin preparation (Fig. 3b, lane 2). The apparent molecular size of this protein coincided with that calculated from the deduced amino acid sequence of the protein encoded by $b c e T$. Without IPTG-induction, no protein band was observed at this position.

\section{Biological activities of the $E$. coli lysate}

The lysate of E. coli JM109(pAGA118) was assayed for biological activities which are characteristic of the diarrhoeal enterotoxin of $B$. cereus. The lysate of $E$. coli JM109(pAGA118) induced with IPTG exhibited $530 \mathrm{CTU}, 1200 \mathrm{PFU}, 75 \mathrm{MLU}$, and $12 \mathrm{DU}$ (mg protein) ${ }^{-1}$; lysates of JM109, or of JM109(pAGA118) not induced with IPTG, had none of these activities. This indicates that the gene was transcribed and translated in $E$. coli, and the gene product might be secreted into the periplasm. In conclusion, the $b c e T$ gene on pAGA118 was responsible for at least part of the activities of bc-D-ENT. However, the concentration of the active substance in the lysate of JM109(pAGA118) after induction with IPTG was apparently much lower than that in the culture supernatant of the parent $B$. cereus B-4ac.

\section{Detection of the bceT gene in other $B$. cereus isolates}

All 10 strains listed in Table 1, including four strains obtained from 'diarrhoeal syndrome' foodborne illness, three strains from 'emetic syndrome' foodborne illness and three strains isolated from soil and from raw and cooked rice, were PCR-positive with amplified DNA bands at the same position ( $428 \mathrm{bp}$ ) after agarose gel electrophoresis (data not shown). This is consistent with the observation that the culture supernatants of all 10 strains, regardless of source, were positive for VP and CT activity (Table 1).

\section{DISCUSSION}

Previous studies from various laboratories have presented different results on the number of components responsible for the activities of bc-D-ENT and on the molecular mass of each component. Turnbull et al. (1979b) reported that the intestinonecrotic toxin, which was considered to be the same as the diarrhoeal enterotoxin, was a single relatively unstable protein with an approximate molecular mass of $50 \mathrm{kDa}$ and an isoelectric point of about 4.9 . On the other hand, Thompson et al. (1984) found experimental evidence for a probable multicomponent or subunit enterotoxin structure. Three antigenic components were identified by chromatographic separation of extracellular proteins produced by $B$. cereus B-4ac. These components were estimated to be proteins of $38,39.5$ and $43 \mathrm{kDa}$. Fractions which contained only one or two of the three components exhibited no toxic activity. When the two nontoxic fractions were combined, activities in all of the biological assays recovered. Beecher \& Macmillan (1991) also reported that three components $(35,36$ and $45 \mathrm{kDa}$, respectively) were necessary to produce oedema and blueing in a rabbit vascular permeability assay, and these activities were ascribed to the bc-D-ENT. These three proteins were originally identified as the components of the haemolysin BL of B. cereus. Granum \& Nissen (1993) determined the sequence of the first 14-15 amino acids of their identified three components. The $\mathrm{N}$ terminal amino acid sequence of bc-D-ENT protein that we deduced from the DNA sequence has no homology with these proteins. Shinagawa et al. (1991) reported that the purified enterotoxin was a single, electrophoretically homogeneous protein with a molecular mass of $45 \mathrm{kDa}$ and an isoelectric point of about $5 \cdot 5$.

Our cloned bce $T$ gene encodes a single protein of calculated molecular mass $41039 \mathrm{Da}$, and E. coli bearing this clone produced a biologically active substance which exhibited cytotoxic activity, positive vascular permeability reaction, mouse lethal activity and fluid accumulation in a ligated mouse ileal loop. All these activities fulfil the criteria of the diarrhoeal enterotoxins. We therefore conclude that bc-D-ENT is one of the enterotoxic proteins of $B$. cereus. Although the biological activities of bc-D-ENT were detected in the cell lysate of JM109(pAGA118), the level of the activities was much lower than that in the culture supernatant of the parent $B$. cereus strain. The $b c e T$ gene should be transcribed from the lac $Z$ promoter of pHSG299, since without addition of IPTG, the level of the activities of the cell lysate was far lower than that of the IPTG-induced cell lysate. The presence of potential terminators in the three directly repeated sequences upstream of the ORF sequence may 


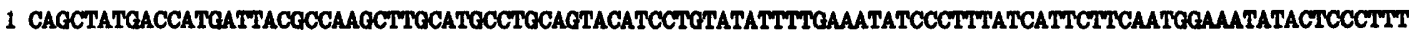
101 TTGTAAAGACACTICATACAGGTTCATACCACTGATTAOTTCTAAACATAATGACTATCTATCTCCTCCTRAACTATCTCAAAGTTATTTCCTACTGOT 201 OTAGATAaATAGTTGTTACAACCTTCTTTATAAATGATTTTCTCAAACCTATTOTTGTATTCACATCACAATTTAAMACATATTTAACCOTOTTTTCAT 301 CAAAATTATTGATAGAATAGATTGTCGOTAATAAAACATCTOCTTGAGAaGTAAATCTACOCTGGAAATGTTTAAAAAACATCACCOATCCCCCAATTCO 401 ACTTATITTTCTTCCCTTPTTCCATAGCTTCATTACTGITCCITHTAAAGGAGAATTCGITATGTACTAAGCTACTTGITTTCTAAACTAAAACTTATAT

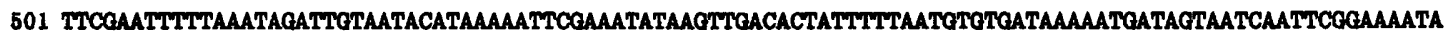

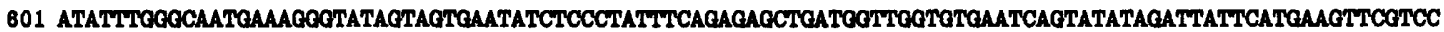

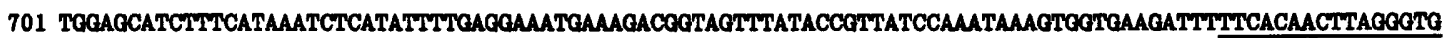

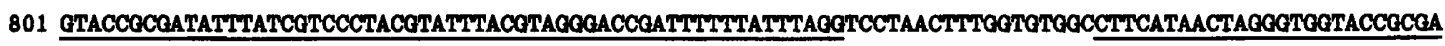

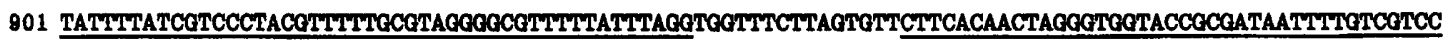

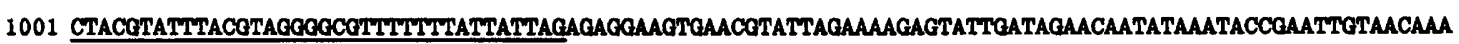

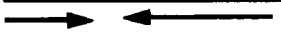

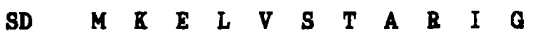

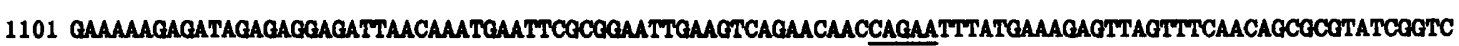

$\begin{array}{llllllllllllllllllllllllllllllllll}\text { B } & \text { S } & \text { L } & \text { G } & \text { I } & \text { G } & \text { L } & \text { I } & \text { L } & \text { A } & \text { T } & \text { Q } & \text { I } & \text { P } & \text { S } & \text { G } & \text { V } & \text { V } & \text { D } & \text { D } & Q & \text { I } & \text { W } & \text { S } & \text { N } & \text { S } & \text { I } & \text { P } & \text { I } & \text { L } & \text { A } & \text { L } & \text { I } & \text { V }\end{array}$ 1201 GTTCACTCGGGATCCAITTAATATTAGCTACGCAMAACCGAGTQGTGTTGTAGATGATCAMATTTGGAGTAACTCGAAATTCAAACTAGCATTAAAAGT

$\begin{array}{lllllllllllllllllllllllllllllllllll}\text { Q } & N & \text { T } & \text { S } & \text { D } & \text { S } & \text { N } & \text { E } & \text { I } & \text { L } & \text { E } & \text { T } & \text { P } & \text { D } & \text { A } & \text { A } & \text { E } & \text { I } & \text { T } & \text { L } & \text { P } & \text { G } & \text { B } & \text { A } & \text { Y } & \text { L } & \text { Q } & \text { V } & \text { G } & \text { N } & \text { N } & E & \text { I }\end{array}$

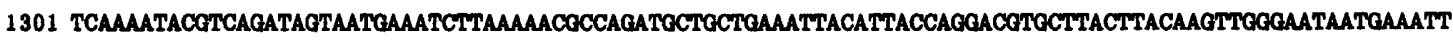

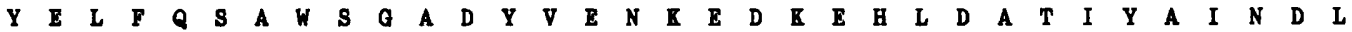
1401 TATGAaCTATTCCAATCAGCTTGGAGCGOAGCAGACTATOTAGAAACAAGGAGGATAAAGAACATTTAGACGCAACAATCTATGCAATAAATGATCTAG

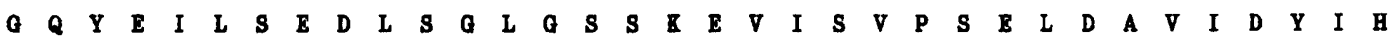
1501 GACAATATGAAATATTAaGTGAaGATTTAaGTOQCCTTGGTAGCAGTAAaGAaGTAATAAGCGTACCATCTGAaCTGGATGCTOTTATTGACTACATTCA

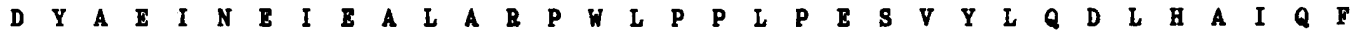

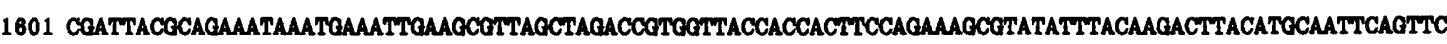

$\begin{array}{lllllllllllllllllllllllllllllllllll}\text { I } & \text { E } & \text { A } & \text { W } & \text { A } & \text { I } & \text { E } & \text { I } & \text { I } & \text { P } & \text { L } & \text { Q } & \text { A } & \text { T } & \nabla & \text { O } & \text { I } & \text { L } & \text { D } & \text { Q } & \text { P } & \text { E } & \text { I } & \text { Q } & \text { S } & \text { Q } & \text { T } & \text { P } & \text { L } & \text { T } & \text { L } & \text { D } & \text { I }\end{array}$

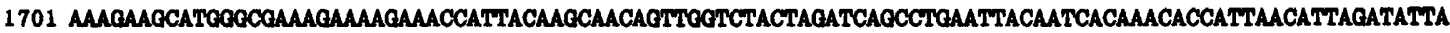

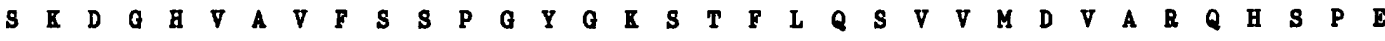
1801 GTAAAGACGGACACOTAGCGGTCITCTCAAGCCCAGGCTACGGAAAATCAACATTCTTACAATCAGTCGITATOGATGTAGCTCGTCAGCATAGTCCGGA

$\begin{array}{llllllllllllllllllllllllllllllllll}\text { 日 } & \text { L } & \text { 日 } & \text { V } & \text { Y } & \text { L } & \boldsymbol{V} & \text { D } & \text { L } & \text { O } & \text { T } & \text { N } & \text { G } & \text { L } & \text { L } & \text { P } & \text { L } & \text { B } & \text { G } & \text { L } & \text { P } & \text { B } & \text { V } & \text { A } & \text { D } & \text { T } & \text { I } & \text { T } & \text { I } & \text { D } & \text { E } & \text { S } & \text { E }\end{array}$

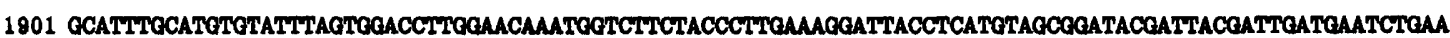

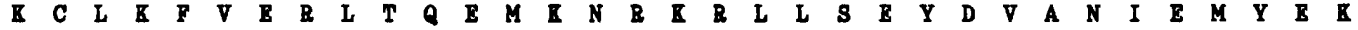

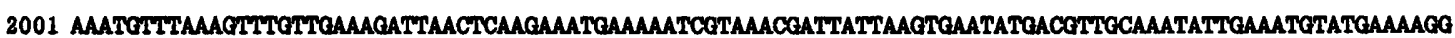

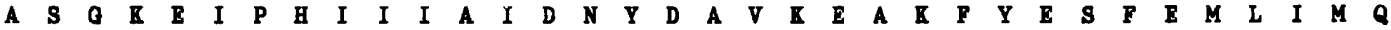

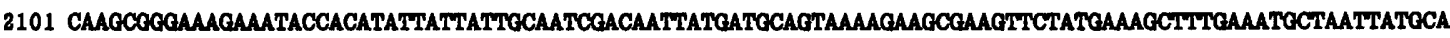

I $\quad \boldsymbol{V}$ C

2201 AATTQTCCOAGATGGTGCAAGTTTAGGAATTCTATTCTTCTATGTCTTCTYTTACTTCGGCGGATAAAATGTCTTCAGCAAACTTCTTGTAGCCATTATA

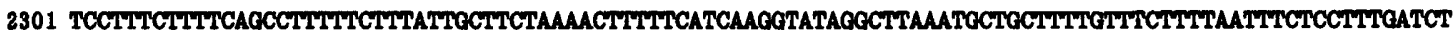

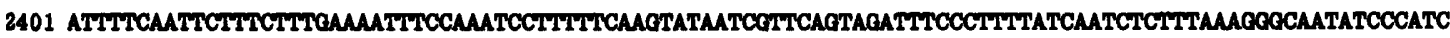

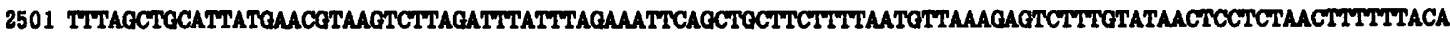

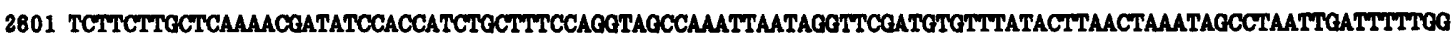
2701 TTAAACCTACTCTATCGCATGCCTCTTCTAAAGATAMATAGTTCATTTCTCACCTCATCCGAAACITTCATTCTAGCTGTTGITTAAACTTTCTTAGTIG 2801 ATATTTTGTTAAACCTGTHTCTITTACTACATCTOTGATTOAATACTCCTTATACTOCAGGTCGACTCTAGAGCATCC

Fig. 2. Nucleotide sequence of the $B$. cereus bce $T$ gene and the flanking region; the deduced amino acid sequence is shown above the nucleotide sequence. A putative ribosome-binding site (SD) and direct repeats are underlined. An asterisk denotes the termination codon and arrows indicate stem-loop structures. 
(a)

(b)

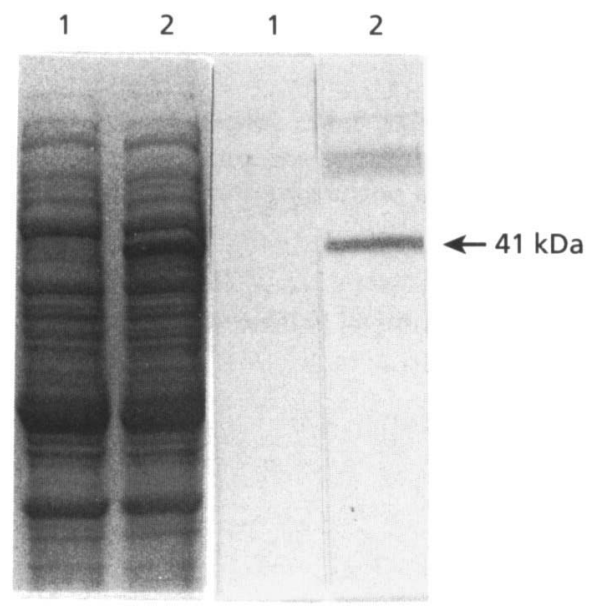

Fig. 3. SDS-polyacrylamide gel (a), and Western blot analysis (b) of a cell lysate of $E$. coli JM109(pAGA118). The arrow indicates the expected $41 \mathrm{kDa}$ protein. Lanes 1, total protein from uninduced JM109 lysate; lanes 2, total protein from induced JM109(pAGA118) lysate.

Table 1. B. cereus strains used in this study

\begin{tabular}{|c|c|c|c|c|c|}
\hline \multirow[t]{2}{*}{ Strain* } & \multicolumn{4}{|c|}{ Properties $\dagger$} & \multirow[t]{2}{*}{ Source } \\
\hline & MIL & ML & VP & CT & \\
\hline B-4ac & ++ & ++ & ++ & ++ & \multirow{4}{*}{$\begin{array}{l}\text { 'Diarrhoeal syndrome' } \\
\text { food poisoning }\end{array}$} \\
\hline D-1 & ++ & ++ & ++ & ++ & \\
\hline D-2 & ++ & ++ & ++ & ++ & \\
\hline D-3 & ++ & ++ & ++ & ++ & \\
\hline E-1 & - & - & ++ & ++7 & \multirow{3}{*}{$\begin{array}{l}\text { 'Emetic syndrome' } \\
\text { food poisoning }\end{array}$} \\
\hline E-2 & - & - & ++ & + & \\
\hline E-3 & - & - & ++ & ++ & \\
\hline $\mathrm{N}-1$ & ++ & ++ & ++ & ++ & Raw rice \\
\hline $\mathrm{N}-2$ & - & - & ++ & ++ & Cooked rice \\
\hline $\mathrm{N}-3$ & + & ++ & ++ & ++ & Soil \\
\hline
\end{tabular}

* All strains were phenotypically the same in motility, indole production, nitrate reduction, Voges-Proskauer reaction and urease production. B-4ac, D-1, D-2, D-3, N-1 and N-3 were positive in the starch hydrolysis test; the other strains were negative.

† Assays for enterotoxin activity: MIL, mouse ileal loop; ML, mouse lethal; VP, vascular permeability; CT, cytotoxicity. ++ , Strongly positive, + , weakly positive, - , negative.

interfere with the transcription of the gene from the lac promoter in E. coli. The bceT gene product is a unique protein: no homologous protein has been reported previously. However, the DNA sequence corresponding to this gene was detected by PCR in all of the B. cereus strains examined. Regardless of source, the culture supernatants of all these strains were positive in some of the enterotoxin activities. It is therefore possible that isolates from food or soil may be candidates for causing diarrhoea-type food poisoning.

\section{ACKNOWLEDGEMENTS}

This work was supported by a grant for scientific research from Yakult Co. Ltd., Tokyo, Japan.

\section{REFERENCES}

Beecher, D. J. \& Macmillan, J. D. (1991). Characterization of the components of hemolysin BL from Bacillus cereus. Infect Immun 59, 1778-1784.

Bonventre, P. F. (1965). Differential cytotoxicity of Bacillus anthracis and Bacillus cereus culture filtrates. J Bacteriol 90, 284-285.

Dubnau, D. \& Davidoff-Abelson, R. (1971). Fate of transforming DNA following uptake by competent Bacillus subtilis. I. Formation and properties of the donor-recipient complex. $J$ Mol Biol 56, 209-221.

Gilbert, R. J. \& Kramer, J. M. (1984). Bacillus cereus enterotoxin: present status. Biocbem Soc Trans 12, 198-200.

Gilmore, M. S., Gilmore, K. S. \& Goebel, W. (1985). A new strategy for ordered DNA sequencing based on a novel method for the rapid purification of near-milligram quantities of a cloned restriction fragment. Gene Anal Tech 2, 108-114.

Glatz, B. A. \& Goefert, J. M. (1973). Extracellular factor synthesized by Bacillus cereus which evokes a dermal reaction in guinea pigs. Infect Immun 8, 25-29.

Glatz, B. A., Spira, W. M. \& Goefert, J. M. (1974). Alteration of vascular permeability in rabbits by culture filtrates of Bacillus cereus and related species. Infect Immun 10, 299-303.

Granum, P. E. \& Nissen, H. (1993). Sphingomyelinase is part of the 'enterotoxin complex' produced by Bacillus cereus. FEMS Microbiol Lett 110, 97-100.

Konowalchuk, J., Speirs, J. I. \& Staric, S. (1977). Vero response to a cytotoxin of Escherichia coli. Infect Immun 18, 775-779.

Kramer, J. M. \& Gilbert, R. J. (1988). Bacillus cereus and other Bacillus species. In Foodborne Bacterial Pathogens, pp. 21-70. Edited by M. P. Doyle. New York: Marcel Dekker.

Laemmli, U. K. (1970). Cleavage of structural proteins during the assembly of the head of bacteriophage T4. Nature 227, 680-685.

Maniatis, T., Fritsch, E. F. \& Sambrook, J. (1982). Molecular Cloning: a Laboratory Manual. Cold Spring Harbor, NY: Cold Spring Harbor Laboratory.

Miller, J. H. (1992). A Short Course in Bacterial Genetics. Cold Spring Harbor, NY: Cold Spring Harbor Laboratory.

Ohta, M., Ina, K., Kusuzaki, K., Kido, N., Arakawa, Y. \& Kato, N. (1991). Cloning and expression of the rfe-rff gene cluster of Eschericbia coli. Mol Microbiol 5, 1853-1862.

Punyashthiti, K. \& Finkelstein, R. A. (1971). Enteropathogenicity of Eschericbia coli. I. Evaluation of mouse intestinal loops. Infect Immun 4, 473-478.

Shinagawa, K., Sugiyama, J., Terada, T., Matsusaka, N. \& Sugii, N. (1991). Improved methods for purification of an enterotoxin produced by Bacillus cereus. FEMS Microbiol Lett 80, 1-6.

Spira, W. M. \& Goefert, J. M. (1975). Biological characteristics of an enterotoxin produced by Bacillus cereus. Can J Microbiol 21, $1236-1246$. 
Takeshita, S., Sato, M., Toba, M., Masahashi, W. \& Hashimoto, T. (1987). High-copy-number and low-copy-number plasmid vectors for lac $Z$ alpha-complementation and chloramphenicol- or kanamycin-resistance selection. Gene 61, 63-74.

Thompson, N. E., Ketterhagen, M. J., Bergdoll, M. S. \& Scanz, E. J.

(1984). Isolation and some properties of an enterotoxin produced by Bacillus cereus. Infect Immun 43, 887-894.

Turnbull, P. C. B. (1976). Studies on the production of enterotoxins by Bacillus cereus. J Clin Pathol 29, 941-948.

Turnbull, P. C. B. (1981). Bacillus cereus toxins. Pharmacol Ther 13, 453-505.
Turnbull, P. C. B., Jorgensen, K., Kramer, J. M., Gilbert, R. J. \& Parry, J. M. (1979a). Severe clinical conditions associated with Bacillus cereus and the apparent involvement of exotoxins. J Clin Patbol 32, 289-293.

Turnbull, P. C. B., Kramer, J. M., Jorgensen, K., Gilbert, R. J. \& Melling, J. (1979b). Properties and production characteristics of vomiting, diarrheal, and necrotizing toxins of Bacillus cereus. Am J Clin Nutr 32, 219-228.

Received 30 August 1994; revised 16 November 1994; accepted 16 December 1994. 